\title{
Match Injury Rates in Professional Soccer Vary With Match Result, Match Venue, and Type of Competition
}

\author{
Hakan Bengtsson, Jan Ekstrand, Markus Waldén and Martin Hägglund
}

\author{
Linköping University Post Print
}

\section{Tweet}

N.B.: When citing this work, cite the original article.

Original Publication:

Hakan Bengtsson, Jan Ekstrand, Markus Waldén and Martin Hägglund, Match Injury Rates in Professional Soccer Vary With Match Result, Match Venue, and Type of Competition, 2013, American Journal of Sports Medicine, (41), 7, 1505-1510.

http://dx.doi.org/10.1177/0363546513486769

Copyright: SAGE Publications (UK and US)

http://www.uk.sagepub.com/home.nav

Postprint available at: Linköping University Electronic Press

http://urn.kb.se/resolve?urn=urn:nbn:se:liu:diva-105047 
Match injury rates in professional soccer vary with match result, match venue and the importance of the competition

Håkan Bengtsson, ${ }^{1}$ PT, Jan Ekstrand,,${ }^{1,2,3}$ MD, PhD, Markus Waldén, ${ }^{1,3}$ MD, PhD, Martin Hägglund, ${ }^{1,4}$ PT, PhD.

${ }^{1}$ Football Research Group, Linköping University, Linköping, Sweden

${ }^{2}$ UEFA Medical Committee, Nyon, Switzerland

${ }^{3}$ Division of Community Medicine, Department of Medical and Health Sciences, Linköping University, Linköping, Sweden

${ }^{4}$ Division of Physiotherapy, Department of Medical and Health Sciences, Linköping University, Linköping, Sweden

\section{Acknowledgements}

The authors would like to thank the participating teams (coaching and technical staff, medical teams and players) for their participation in the study. Henrik Magnusson, MSc, statistician, is acknowledged for help with database management and statistical support. 


\section{ABSTRACT}

Background: Player activities in soccer matches are influenced by the match result and match venue. It is not known if injury rates are influenced by these factors.

Purpose: To investigate if there are associations between injury rates and the match result, venue and type of competition in male soccer.

Study Design: Cohort study

Methods: 26 professional clubs from 10 countries were followed prospectively during nine seasons (2001/02 to 2009/10). All matches, and injuries occurring in these matches, were registered by the team's medical staff. An injury was registered if it resulted in absence from training or match. Information about match result, venue and type of competition for all reported matches were gathered by the authors from online databases. Injury rates in matches with varying match characteristics were compared using Generalized Estimating Equations. Odds ratios (ORs) with 95\% confidence intervals (CIs) were calculated.

Results: During 6010 matches 2738 injuries were registered. There were no associations between odds of one injury occurrence and match result or type of competition, while the odds was decreased in matches played away compared with home matches $(\mathrm{OR}, 0.89 ; 95 \%$ CI, 0.80-0.99). The odds of two or more injury occurrences in a match was increased in matches drawn (OR, 1.39; 95\% CI, 1.15-1.69) or lost (OR, 1.66; 95\% CI, 1.38-1.98) compared with matches won, while decreased in other cup matches compared with league matches (OR, 0.57; 95\% CI, 0.39-0.84) and in matches played away compared with home matches (OR, 0.70; 95\% CI, 0.60-0.82). Finally, injuries with more than one week absence occurred more frequently in Champions league matches compared with league matches both for matches with one injury (OR, 1.26; 95\% CI, 1.09-1.45) and two or more injuries (OR, 1.57; 95\% CI, 1.13-2.20). 
Conclusion: The odds of two or more injury occurrences in professional soccer was higher in matches lost and drawn compared with matches won, while the odds of injury occurrences was lower in matches played away compared with home matches. The rate of moderate and severe injuries increased with the importance of the match.

\section{Key Terms:}

Athletic injuries, competition, football, performance, risk factors

What is known about the subject: Player activities in professional soccer vary with different match characteristics, but it is not known if injury rates are influenced by these factors.

What this study adds to existing knowledge: This study showed that the rate of injuries with absence more than one week increased with the importance of the match in professional soccer. Furthermore, an association between injury rates and match result was found which may be of importance in future efforts to implement preventive measures. 


\section{INTRODUCTION}

The rate of time loss injuries in professional European soccer matches has been shown to be between 24.6-28.2 time loss injuries/1000 match hours. ${ }^{2,11,19}$ There are many factors that may contribute to injury occurrences in sports, and these are usually divided into intrinsic risk factors, such as age and flexibility, and extrinsic risk factors, such as physical load and variation in playing surface. ${ }^{4}$ While many studies have focused on intrinsic risk factors for injuries in soccer, $\mathbf{2 , 8 , 1 4 , 1 6}$ studies on extrinsic risk factors are fewer.

Previous studies have shown associations between match characteristics and playing activity. "The home advantage", for example, is a well-established phenomenon and is shown by the fact that home teams are more likely to win, ${ }^{\mathbf{2 0 , 2 2 , 2 3}}$ have more shots on and off target and have more ball possession, ${ }^{\mathbf{2 0 , 2 2}}$ especially in the attacking zone of the playing field compared with away teams. ${ }^{22}$ In addition, less foul play decisions are taken by the referee against the home team.

Few studies have examined whether match result, match venue and type of competition influence injury rates in soccer. ${ }^{7,13,18}$ In one study on a French professional soccer team followed during four consecutive seasons, no significant difference in injury rates in domestic matches compared with European Cup matches was shown. ${ }^{7}$ Two studies have investigated the association between match injury rate and match result. One of these, including youth and senior national teams competing in European Championships, showed no association, ${ }^{\mathbf{1 8}}$ while the other, studying the Swedish senior national team, showed that the injury rate was increased during matches lost compared with matches won or drawn. ${ }^{\mathbf{1 3}}$ The latter study also investigated if the injury rate was influenced by match venue, but found no association.

There are thus only few studies investigating the association between different match characteristics and injury rates in soccer and they are all limited by relatively small samples. 
The aim of this study was therefore to analyse the association between different match characteristics and injury occurrence in a large sample of male professional soccer players. Even though scientific data are scarce, we hypothesized that there would be higher injury rates in matches lost compared with matches won, in matches played away compared with played at the home venue, and in matches played in European cups compared with the domestic league. 


\section{MATERIALS AND METHODS}

\section{Participants}

The Union of European Football Associations (UEFA) injury study was initiated in 2001, ${ }^{11}$ and the present study is a retrospective sub analysis, of prospectively collected data, on match exposure and injuries over nine consecutive seasons between 2001 and 2010. The validation of the methodology and the general procedure of injury and exposure registration have been described in detail earlier, ${ }^{17}$ and is therefore only briefly summarized below.

\section{Inclusion and exclusion criteria}

The study cohort consisted of 26 professional soccer clubs from ten European countries. All clubs competed at the highest club level of male soccer. All players in the first teams were invited to take part in the study. If any of the invited clubs failed to deliver complete data to the study group the club was excluded from the study.

\section{Exposure and Injury Registration}

All first team matches were registered on a standard attendance record. In addition, the club medical officer registered all injuries that occurred during these matches on an injury form. A recordable injury was defined as an injury occurring during a soccer match that results in a player being unable to take full part in future soccer training or match play, i.e. a time loss injury. ${ }^{15,17}$ A player was considered to be injured, and marked as absent on the attendance record, until the medical team allowed full participation in all team activities. Injury severity was categorized according to the number of days absence (slight/minimal 0-3 days, mild 4-7 days, moderate $8-28$ days, and severe $>28$ days). ${ }^{17}$ Registration of injury occurrences due to foul play was based on the decision of the match referee. The injury forms and attendance records were returned to the study group on a monthly basis. The monthly reports were 
reviewed by a member of the study group and prompt feedback was sent to the clubs to complete missing data and clarify any uncertainties, if necessary.

Information about match result (match won, drawn or lost), match venue (neutral venue, home or away match) and type of competition (friendly, league, UEFA Champions League, UEFA Europa League [former UEFA Cup], or other cup match [mainly domestic cup matches]) were collected for each first team match included on the clubs' attendance records. In case a match went to extra time or penalties, the match result after 90 minutes, including possible added time, was used as the final match result. All matches that were part of the domestic cups as well as matches in international cups other than UEFA Champions League, UEFA Europa League and friendly tournaments were categorized as other cup matches. Friendly matches ( $\mathrm{n}=980,13 \%)$ were excluded from the analyses since these matches were considered to have different characteristics than competitive matches. In addition, matches played at a neutral venue $(n=78,1 \%)$ were excluded due to the limited number of matches.

The authors used online databases, primarily the included clubs' official homepages, to retrieve data about the aforementioned match characteristics. All collected data were controlled with at least one additional online database.

\section{Ethics}

Individual written informed consent was obtained from all participating players. The study design and methodology was approved by the UEFA Football Development Division and the UEFA Medical Committee.

\section{Data Analysis}

Several Generalized Estimating Equations (GEE) with logit link were fitted on match level data, with each first team competitive match as an observation. GEE allows modelling of correlated observations, repeated measures within each team, by specification of the working 
correlation structure. The SPSS procedure GENLIN (link = logit, distribution = binomial, working correlation structure $=$ independent) was used. Injury occurrences per team, classified as zero injuries, one injury, and two or more injuries, were used as a primary response variable. Two separate models were fitted on injury occurrence (zero vs. one injury and zero vs. two or more injuries) with match results, match venue and type of competition as explanatory variables. As an indication of model goodness of fit, the Corrected Quasi likelihood under Independence model Criterion (QICC) was used. Independent working correlation structure generated the lowest QICC in the models. As a sensitivity analysis, additional models were fitted including only moderate and severe injuries with more than one week's absence.

Match results, classified as won, draw, and lost, was used as a secondary response variable. Two separate models were fitted on match results (won vs. draw and won vs. lost) with injury occurrence, match venue and type of competition as explanatory variables. All models were adjusted for recovery time between matches ( $\leq 3$ days recovery vs. $>3$ days recovery).

Associations between categorical variables (injury types, injury location, foul play and match characteristics) were analysed with Pearson's Chi-square test and additional z-test for pairwise comparisons of proportions, using Bonferroni correction to adjust for multiple comparisons. All tests were two-sided and the significance level was set at $\mathrm{P}<.05$. 


\section{RESULTS}

There were 2738 injuries registered during 6010 competitive matches, the majority of them being league matches (Table 1).

\section{Influence of Match Characteristics on Injury Occurrence}

Initial analyses of the odds of one injury occurrence in a match showed no statistically significant associations between match result, or the type of competition, with injury occurrence, while away matches were associated with a decreased odds of injury occurrence compared with matches played at home (Table 2). In the analyses with two or more injury occurrences, the odds was increased in matches drawn or lost compared with matches won, and decreased in other cup matches compared with league matches as well as in matches played away compared with home matches (Table 2).

In the analyses of injuries with more than one week's absence, the same pattern for associations between match characteristics and injury occurrences persisted (Table 2). In addition, a statistically significant association between type of competition and injury occurrence was found, with an increased odds of one, as well as two or more injury occurrences, in UEFA Champions League matches compared with league matches.

\section{Injury Patterns Depending on Match Characteristics}

There were no differences in injury proportions regarding injury type and location based on match result or type of competition (Table 3). There was, however, a significant overall difference of injury type proportions based on match venue, with a higher proportion of muscle/tendon injuries, and lower proportion of joint/ligament injuries, in home matches. There was also a significant overall difference in the proportion of injury locations for 
different match venues. No differences in the proportion of injuries caused by foul play were shown for any of the match characteristics.

\section{Influence of Injury Occurrences on Match Results}

An association between injury occurrences in a match and the match result was found, where the odds of a match lost (OR, 1.60; 95\% CI, 1.33-1.93) or drawn (OR, 1.38; 95\% CI, 1.141.67) was greater in matches with two or more injury occurrences compared with matches with no injury. There was no statistically significant association between one injury in a match and the match result. 


\section{DISCUSSION}

The major finding of this study was that there were several statistical effects of match characteristics on injury occurrence in professional European soccer. Briefly, the odds of two or more injury occurrences in a given match was significantly higher in matches lost or drawn compared with matches won, in home matches compared with away matches, and in UEFA Champions League matches compared with league matches. Furthermore, injuries influenced match results, where the odds of a match ending with a loss or draw, as compared with a win, was increased in matches where two or more injuries occurred than in matches with no injury.

\section{Highest Injury Rate in the Champions League}

The UEFA Champions League is the most prestigious and important of all competitions in professional European soccer and was associated with an increased rate of injuries with more than one week's absence compared with league matches. A possible explanation for this association is that the intensity in important matches might be higher than in matches of less importance which, in turn, may lead to higher injury rates. It is also possible that the importance of a competition may influence a teams' will to let players with minor, not fully rehabilitated, injuries play and this may be reflected in our results as an increased injury rate. Injury recurrences are common in professional soccer and it has been suggested that this is due to insufficient rehabilitation, ${ }^{2}$ but it may also be a calculated risk to let players with minor complaints participate in an important match.

Our findings were not in accordance with a previous study where a French professional soccer team was followed during four seasons where no difference in injury rates was found between European cup matches and domestic matches. ${ }^{7}$ In that study the injury rate in all European cup matches (UEFA Europa League and UEFA Champions League matches) were compared with all domestic matches (cup and league matches combined), while in the present study all of 
these different competitions were analysed separately. This difference in the study designs makes it difficult to compare the results between the two studies.

\section{Injuries More Frequent in Home Matches}

The present study showed associations between a decreased injury rate and playing away matches, and that the injury type and location proportions varied somewhat depending on match venue. A possible explanation for these findings may be the difference in match activity and playing strategy between the home and away team showed in several studies. ${ }^{\mathbf{2 0 , 2 2 , 2 3}}$ This is, however, speculative and the reason for the observed association between decreased injury rates and away matches, as well as the reason for the slight variation in injury pattern, needs to be studied further. To the authors' knowledge the association between match venue and injury rate has only been studied in one previous study showing no difference in injury rates between matches played at home, away or on a neutral venue. ${ }^{13}$ This study was carried out in a national team setting exclusively which makes comparisons with the present study difficult.

\section{Fewer Injuries in Matches Won}

The present study showed that the odds of injury occurrences was greater in matches lost and drawn compared with matches won. One possible explanation why injury rates would increase when the team is losing or drawing a match is that the match result could influence a team's match strategy. Previous studies have shown that soccer players perform less high intensity activities when winning a match compared with when losing, ${ }^{9,21}$ and it is possible that this decrease of high intensity activities results in a decrease in injury rate.

\section{Decreased Odds of Winning in Matches with Injury Occurrences}


The study also showed that the odds that a team would lose or draw a match were greater when the team sustained two or more injuries during the match. Previous studies have found associations between injuries and team success in club soccer, with a correlation between final league standing and the number of injury days per team ${ }^{1}$ as well as correlations between injury incidence and team success. ${ }^{\mathbf{1 0}}$

A similar trend has also been shown in national team soccer, where teams that were eliminated in the group stage of the 2005 Women's European Championships had a higher injury rate than teams that advanced to the semifinals. ${ }^{24}$ In addition, a few previous studies have analyzed the association between match results and injury rates, but with conflicting results. ${ }^{13,18}$ One study showed a higher injury rate in matches lost compared with matches won or drawn, ${ }^{\mathbf{1 3}}$ as the present study indicates, while the other showed no relationship between injury rates and match results. ${ }^{18}$

Injury occurrences may decrease team performance by forcing the team to a substitution, thus affecting the game plan. ${ }^{\mathbf{1 3}}$ It is, however, not uncommon that a player is able to complete a match even though he has sustained an injury, and the association between such injuries and the match result may therefore be less obvious. Even so, it is still possible that an injury may affect a player's ability to perform even though it does not lead to out-of-pitch treatment or substitution. ${ }^{3}$

No matter the explanation, the association between injury occurrences and match result is an interesting finding that merits more research. Future studies should focus on establishing whether or not there is a causal relationship between low injury rates and team success since establishing such a relationship may be the most effective way of enhancing the priority of preventive measures in professional soccer clubs. 


\section{Methodological Considerations}

The prospective design of the study, the large number of matches and injuries included, the homogenous group of professional soccer players studied, and injury surveillance being carried out in harmonization with the methodological consensus in the field were the main strengths of the study.

Some further limitations of our study than those already discussed should be acknowledged. First, data were analysed on team level per match and not on individual player basis. Several teams in our study are prominent and successful clubs involved in many competitive matches and have a congested playing calendar. They usually have large squads and may compete with different players in the various competitions, ${ }^{12}$ and this could possibly be reflected in our findings. For instance, injury rates have been shown to be lower in youth national teams compared with adult national teams, ${ }^{18}$ and younger and less experienced players may have been used more frequently in competitions of less importance. Another potential explanation for our findings is that players might have an increased recognition of injuries and may be more willing to be substituted for injuries of less severity when losing a match than when winning, ${ }^{13}$ but no such qualitative data could be extracted with the present study design. Second, the reliability of our data may be affected in that match characteristics were not collected in the same manner as information about exposure and injuries, but instead were gathered from online databases, and because several different contact persons were responsible for collecting data from different clubs. To ensure as reliable data as possible, exposure and injury data were checked each month by the study group and feedback was sent to the clubs to complete missing data and clarify any uncertainties, if necessary. In addition, all collected data on match characteristics were controlled with at least one additional online database. Finally, a description of the specific injury mechanisms leading up to injury may have helped to explain some of the differences in injury rates identified in the present study, ${ }^{5}$ 
but such descriptions were not collected. It should also be acknowledged that, since the analyses in the present study were all made on a team level, any individual risk factors that are suggested to contribute to the differences in injury rates between different match characteristics and injury rates are speculative and needs to be confirmed in future studies. 


\section{CONCLUSION}

Even though causality cannot be established, the present study showed increased injury rates in matches lost and drawn compared with matches won, and that the odds that a match would end in a draw or loss were increased when a team had sustained two or more injuries during the match, thus suggesting an association between injuries and performance. It was also shown that injury rates were lower in matches that were played away compared with at the home stadium. Finally, injuries with more than one week's absence occurred more frequently in UEFA Champions League than in league matches suggesting that the rate of more severe injuries in professional soccer increased with the importance of the match. 


\section{REFERENCES}

1. Árnason Á, Sigurdsson SB, Gudmundsson A, et al. Physical fitness, injuries, and team performance in soccer. Med Sci Sports Exerc. 2004;36(2):278-285. PMID:14767251

2. Árnason Á, Sigurdsson SB, Gudmundsson A, et al. Risk factors for injuries in football. Am J Sports Med. 2004;32(1 Suppl):5S-16S. PMID:14754854

3. Bahr R. No injuries, but plenty of pain? On the methodology for recording overuse symptoms in sports. Br J Sports Med. 2009;43(13):966-972. PMID: 19945978

4. Bahr R, Holme I. Risk factors for sports injuries--a methodological approach. Br J Sports Med. 2003;37(5):384-392. PMID: 14514527

5.Bahr R, Krosshaug T. Understanding injury mechanisms: a key component of preventing injuries in sport. Br J Sports Med. 2005;39(6):324-329. PMID: 15911600

6. Boyko RH, Boyko AR, Boyko MG. Referee bias contributes to home advantage in English Premiership football. J Sports Sci. 2007;25(11):1185-1194. PMID: 17654230

7.Carling C, Orhant E, LeGall F. Match injuries in professional football: inter-seasonal variation and effects of competition type, match congestion and positional role. Int J Sports Med. 2010;31(4):271-276. PMID: 20166007

8. Chalmers DJ, Samaranayaka A, McNoe BM. Risk factors for injury in community-level football: a cohort study. Int J Inj Contr Saf Promot. 2012 Apr 10; [Epub ahead of print] PMID: 22486184

9. Dupont G, Nedelec M, McCall A, et al. Effect of 2 soccer matches in a week on physical performance and injury rate. Am J Sports Med. 2010;38(9):1752-1758. PMID: 20400751 
10. Eirale C, Tol JL, Farooq A, et al. Low injury rate strongly correlates with team success in Qatari professional football. Br J Sports Med. 2012 Sep; [Epub ahead of print] PMID: 22904292

11. Ekstrand J, Hägglund M, Waldén M. Injury incidence and injury patterns in professional football - the UEFA injury study. Br J Sports Med. 2011;45(7):553-558. PMID: 19553225

12. Ekstrand J, Waldén M, Hägglund M. A congested football calendar and the wellbeing of players: correlation between match exposure of European footballers before the World Cup 2002 and their injuries and performances during that World Cup. Br J Sports Med. 2004;38(4):493-497. PMID: 15273193

13. Ekstrand J, Waldén M, Hägglund M. Risk for injury when playing in a national football team. Scand J Med Sci Sports. 2004;14(1):34-38. PMID: 14723786

14. Engebretsen AH, Myklebust G, Holme I, et al. Intrinsic risk factors for hamstring injuries among male soccer players: a prospective cohort study. Am J Sports Med. 2010;38(6):11471153. PMID: 20335507

15. Fuller CW, Ekstrand J, Junge A, et al. Consensus statement on injury definitions and data collection procedures in studies of football (soccer) injuries. Br J Sports Med. 2006;40(3):193-201. PMID: 16505073

16. Henderson G, Barnes CA, Portas MD. Factors associated with increased propensity for hamstring injury in English Premier League soccer players. J Sci Med Sport. 2010;13(4):397402. PMID: 19800844

17. Hägglund M, Waldén M, Bahr R, et al. Methods for epidemiological study of injuries to professional football players: developing the UEFA model. Br J Sports Med. 2005;39(6):340346. PMID: 15911603 
18. Hägglund M, Waldén M, Ekstrand J. UEFA Injury study--an injury audit of European Championships 2006 to 2008. Br J Sports Med. 2009;43(7):483-489. PMID: 19246461

19. Hawkins RD, Fuller CW. A prospective epidemiological study of injuries in four English professional football clubs. Br J Sports Med. 1999;33(3):196-203. PMID: 10378073

20. Lago C. The influence of match location, quality of opposition, and match status on possession strategies in professional association football. J Sports Sci. 2009;27(13):14631469. PMID: 19757296

21. Lago-Peñas C, Rey E, Lago-Ballesteros J, et al. The influence of a congested calendar on physical performance in elite soccer. J Strength Cond Res. 2011;25(8):2111-2117. PMID: 21572352

22. Poulter DR. Home advantage and player nationality in international club football. $J$ Sports Sci. 2009;27(8):797-805. PMID: 19437186

23. Sánchez PA, García CT, Leo FM. An analysis of home advantage in the top two Spanish professional football leagues. Percept Mot Skills. 2009;108(3):789-797. PMID: 19725315

24. Waldén M, Hägglund M, Ekstrand J. Football injuries during European Championships 2004-2005. Knee Surg Sports Traumatol Arthrosc. 2007;15(9):1155-1162. PMID: 17375283 


\section{TABLE LEGENDS}

Table 1. Number of matches with different match characteristics.

Table 2. Influence of Match Characteristics on Injury Rates.

Table 3. Injury proportions according to injury type, location and foul play depending on match characteristics. 
TABLE 1

Number of Matches With Different Match Characteristics ${ }^{\mathrm{a}}$

\begin{tabular}{|c|c|c|c|c|c|c|}
\hline \multirow[t]{2}{*}{ Competition } & \multirow[t]{2}{*}{ Total } & \multicolumn{2}{|c|}{ Match Venue } & \multicolumn{3}{|c|}{ Match Result } \\
\hline & & Home & Away & Won & Draw & Lost \\
\hline League, n (\%) & 4193 & $2096(50)$ & $2097(50)$ & $2469(59)$ & $965(23)$ & $759(18)$ \\
\hline UCL, n (\%) & 849 & $422(50)$ & $427(50)$ & $404(48)$ & $214(25)$ & $231(27)$ \\
\hline $\mathrm{EL}, \mathrm{n}(\%)$ & 294 & $147(50)$ & $147(50)$ & $157(53)$ & $68(23)$ & $69(23)$ \\
\hline Other Cup, n (\%) & 674 & $332(49)$ & $342(51)$ & $398(59)$ & $140(21)$ & $136(20)$ \\
\hline Total, n (\%) & 6010 & $2997(50)$ & $3013(50)$ & $3428(57)$ & $1387(23)$ & $1195(20)$ \\
\hline
\end{tabular}

aUCL, UEFA Champions League; EL, Europa League. 
TABLE 2

Influence of Match Characteristics on Injury Rates.

\begin{tabular}{|c|c|c|c|c|c|c|c|c|c|c|c|c|}
\hline & \multicolumn{6}{|c|}{ All Time Loss Injuries } & \multicolumn{6}{|c|}{ Injuries With More Than One Week Absence } \\
\hline & OR & $95 \% \mathrm{CI}$ & $P$ value & OR & $95 \% \mathrm{CI}$ & $P$ value & OR & $95 \% \mathrm{CI}$ & $P$ value & OR & $95 \% \mathrm{CI}$ & $P$ value \\
\hline \multicolumn{13}{|l|}{ Result } \\
\hline Won $^{\mathrm{a}}$ & 1.0 & & & 1.0 & & & 1.0 & & & 1.0 & & \\
\hline Draw & 1.11 & $0.96-1.29$ & .163 & 1.39 & $1.15-1.69$ & .001 & 1.13 & $0.94-1.34$ & .189 & 2.14 & $1.60-2.88$ & .000 \\
\hline \multicolumn{13}{|l|}{ Competition } \\
\hline League $^{\mathrm{a}}$ & 1.00 & & & 1.0 & & & 1.0 & & & 1.0 & & \\
\hline UCL & 1.15 & $0.95-1.39$ & .145 & 1.27 & $0.95-1.70$ & .106 & 1.26 & $1.09-1.45$ & .001 & 1.57 & $1.13-2.20$ & .008 \\
\hline EL & 0.85 & $0.67-1.07$ & .166 & 0.78 & $0.53-1.14$ & .201 & 0.91 & $0.64-1.28$ & .575 & 0.71 & $0.35-1.43$ & .334 \\
\hline Other cup & 0.88 & $0.74-1.05$ & .148 & 0.57 & $0.39-0.84$ & .004 & 0.90 & $0.74-1.10$ & .299 & 0.63 & $0.42-0.95$ & .029 \\
\hline
\end{tabular}

Odds ratios were calculated using Generalized Estimating Equations

OR, odds ratio; CI, confidence interval; UCL, UEFA Champions League; EL, Europa League.

${ }^{\text {a }}$ Reference group in analysis. 
TABLE 3

Injury Proportions According to Injury Type, Location and Foul Play Depending on Match Characteristics

\begin{tabular}{|c|c|c|c|c|c|c|c|c|c|}
\hline & \multicolumn{4}{|c|}{ Type of competition } & \multicolumn{2}{|c|}{ Match venue } & \multicolumn{3}{|c|}{ Match result } \\
\hline & League & UCL & EL & Other cup & Home & Away & Won & Draw & Lost \\
\hline \multicolumn{10}{|l|}{ Injury type, n (\%) } \\
\hline CNS \& PNS & $39(2)$ & $7(2)$ & $3(3)$ & $4(2)$ & $26(2)$ & $27(2)$ & $32(2)$ & $11(2)$ & $10(2)$ \\
\hline Contusions \& lacerations & $407(21)$ & $85(19)$ & $21(18)$ & $58(23)$ & $301(21)$ & $270(21)$ & $305(21)$ & $132(20)$ & $134(22)$ \\
\hline Fractures and bone stress & $91(5)$ & $21(5)$ & $7(6)$ & $15(6)$ & $64(4)$ & $70(5)$ & $66(5)$ & $35(5)$ & $33(5)$ \\
\hline Joints and ligaments & $471(25)$ & $116(26)$ & $21(18)$ & $66(26)$ & $321(22)^{a}$ & $353(27)^{\mathrm{a}}$ & $356(24)$ & $162(24)$ & $156(26)$ \\
\hline Muscle and tendon & $845(44)$ & 203(45) & $62(53)$ & $110(43)$ & $688(48)^{\mathrm{a}}$ & $532(41)^{\mathrm{a}}$ & $652(45)$ & $308(46)$ & $260(43)$ \\
\hline Other & $59(3)$ & $19(4)$ & $4(3)$ & $4(2)$ & $49(3)$ & $37(3)$ & $46(3)$ & $23(3)$ & $17(3)$ \\
\hline \multicolumn{10}{|l|}{ Injury location, n (\%) } \\
\hline Lower limbs & $1692(89)$ & 399(89) & $103(87)$ & $220(86)$ & $1297(90)^{\mathrm{a}}$ & $1117(87)^{\mathrm{a}}$ & $1281(88)$ & $596(89)$ & $537(88)$ \\
\hline Trunk & $101(5)$ & $25(6)$ & $11(9)$ & $16(6)$ & $85(6)$ & $68(5)$ & $89(6)$ & $37(6)$ & $27(4)$ \\
\hline Upper limbs & $57(3)$ & $10(2)$ & $0(0)$ & $12(5)$ & $33(2)^{a}$ & $46(4)^{\mathrm{a}}$ & $37(3)$ & 19(3) & $23(4)$ \\
\hline Head \& neck & $62(3)$ & $17(4)$ & $4(3)$ & $9(4)$ & $34(2)^{a}$ & $58(5)^{\mathrm{a}}$ & $50(3)$ & 19(3) & $23(4)$ \\
\hline \multicolumn{10}{|l|}{ Foul play, n (\%)b } \\
\hline No foul & $1523(80)$ & $362(81)$ & $99(85)$ & $206(81)$ & $1164(81)$ & $1026(80)$ & $1154(80)$ & $544(81)$ & $492(81)$ \\
\hline Opponent foul & $367(19)$ & $83(19)$ & $18(15)$ & $48(19)$ & $268(19)$ & $248(19)$ & $290(20)$ & $121(18)$ & $105(17)$ \\
\hline Own foul & $16(1)$ & $3(1)$ & $0(0)$ & $2(1)$ & $9(1)$ & $12(1)$ & $8(1)$ & $5(1)$ & $8(1)$ \\
\hline
\end{tabular}

UCL, UEFA Champions League; EL, Europa League; CNS, Central nervous system; PNS, Peripheral nervous system.

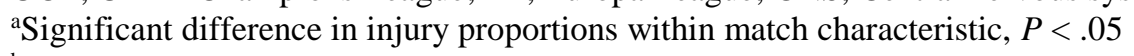

${ }^{\mathrm{b}}$ Information about foul play missing for 11 injuries 